\title{
Utilization of $\mathrm{N}, \mathrm{P}$, and organic $\mathrm{C}$ by heterotrophic bacteria. I. Outline of a chemostat theory with a consistent concept of 'maintenance' metabolism
}

\author{
T. Frede Thingstad \\ Department of Microbiology and Plant Physiology, University of Bergen, Allégt. 70, 5000 Bergen, Norway
}

\begin{abstract}
The effect of variable $\mathrm{N}: \mathrm{C}$ and $\mathrm{P}: \mathrm{C}$ ratios in the reservoir medium on chemostat steadystate situations is explored using idealized mathematical models. A simple 'Monod' type model, with fixed biomass composition and constant yield, is used to guide the general understanding of the outcome to be expected. With this model, 3 uniquely defined areas of reservoir medium $\mathrm{N}: \mathrm{C}$ and $\mathrm{P}: \mathrm{C}$ ratios are discerned, corresponding to either carbon, nitrogen, or phosphorus limitation of bacterial growth. A more elaborate 'Droop' type model, allowing for variable biomass composition and an additional respiration term proportional to the 'surplus' amount of carbon per cell, is shown to introduce additional intermediate areas where the medium is exhausted of combinations of 2 , or of all 3 nutrients. At maximum growth rate, the predictions of the 'Droop' model reduce to those of a 'Monod' type model. The requirement of organic $C$ for energy production is explored at different growth rates and at different types of growth limitation. With previous models there was an unnoted inconsistency between the simultaneous assumptions of mineral nutrient limitation and a non-zero 'maintenance' metabolism as growth rate approached zero. In the model suggested here, the increase in the areas of mixed N, C and $P, C$ limitations at low growth rates eliminates this inconsistency, while still qualitatively explaining existing observational data. From comparison of the model with existing data, 2 further refinements in the description of respiration are suggested. One is the assumption of a difference between the level of cell 'surplus' carbon at which growth stops, and the level at which respiration is halted. The other assumption is a dependence of respiration on phosphate starvation. The model is used to explore the role of bacteria as remineralizers and/or consumers of mineral nutrients. Use of the terms 'maintenance', 'waste', and 'growth independent' metabolism is discussed in light of the concept introduced in the model.
\end{abstract}

\section{INTRODUCTION}

Heterotrophic bacteria need a mixed diet of nitrogen, phosphorus and organic carbon in order to produce new biomass with a balanced composition of these elements. In marine environments, these 3 elements are the ones which primarily would be expected to cause nutrient limitation of bacterial growth. Which of the 3 will become limiting in a given situation would be a function of the ratio between $N, P$ and $C$ in the nutrient sources available, of the value of these ratios in bacterial biomass, and of the amount of organic $\mathrm{C}$ used for bacterial respiration.

In a larger perspective, the activity of heterotrophic bacteria may be seen as one of the points in an ecosystem where transport of carbon through the food web is coupled to the cycling of mineral nutrients. Qualitative and quantitative understanding of the coupling between $\mathrm{C}, \mathrm{N}$ and $\mathrm{P}$ metabolism in heterotrophic bacteria is thus not only important in the field of bacterial physiology, it is also a point at which an adequate concept of bacterial physiology is essential to the understanding of how microbial ecosystems function. Of special interest in this context is the question of whether bacteria act mainly as consumers or as remineralizers of mineral nutrients (Johannes 1968, Mann 1982, Azam et al. 1983)

In an ecosystem context, composition of bacterial biomass is also important, since this defines the quality of food available to bacterivorous organisms. Herbert (1961) pointed out that it is virtually meaningless to speak of the chemical composition of a microorganism without at the same time identifying the environment in which it was growing. Modelling efforts of such 
processes as carbon available to, or mineral nutrients remineralized by, bacterial predators, thus requires an understanding of how bacterial biomass composition is controlled.

In a study of how ecosystem interactions result in a reciprocal relation between glucose degradation and ecosystem structure (Pengerud et al. 1987), 2 different models of bacterial growth were used in theoretical analysis (Thingstad \& Pengerud 1985). Based on the work of Monod (1942) and Droop (1974), these models were termed 'Monod' and 'Droop' type models respectively, a nomenclature which will be retained in the subsequent analysis of a refinement in the 'Droop' type formulation. Due to its simplicity, the 'Monod' model could be used by Thingstad \& Pengerud (1985) as a valuable heuristic tool for exploration of gross features of system behavior. Interesting experimental observations (Pengerud et al. 1987), such as the existence of an extended range of medium $C: P$ ratios for which the bacteria exhausted both of 2 limiting nutrients from the medium were, however, explained by the 'Droop' model only.

Following the same approach, we explore in more detail a submodel for bacterial utilization of $N, P$, and organic C necessary in such food-web studies. This led us to a realization of inconsistencies in the contemporary concept of bacterial 'maintenance' metabolism and we suggest a revised conceptual framework which resolves these inconsistencies

\section{'MONOD' TYPE MODEL}

The basic assumption of the 'Monod' type model as used here is that:

(1) there is a constant $\mathrm{C}: \mathrm{N}: \mathrm{P}$ composition of bacterial biomass, and the respiration coefficient is constant.

A mathematical formulation of this model is not necessary for the present purpose.

A corollary to Assumption 1 is that the model assumes maintenance metabolism to be insignificant, and that yield is independent of growth conditions.

We analyse the outcome of chemostat experiments where the concentration of organic $C$ in the reservoir is kept constant, while the concentrations of the $\mathrm{N}$ and $\mathrm{P}$ sources are varied. For simplicity, the $C, N$ and $P$ sources will for the moment be assumed to be chemically and physically independent, i.e. not chemically bound to each other as may be the case for example with amino acids, or physically associated as may be the case for example during degradation of dead organisms or other particulate material. Assuming further that:
(2) bacterial biomass has a composition given by the Redfield ratio: $\mathrm{C}: \mathrm{N}: \mathrm{P}=106: 16: 1$ (Redfield et al. 1963), and that

(3) respiration coefficient is $50 \%$,

the type of limitation at equilibrium in such cultures may be summarized graphically as shown in Fig. 1.

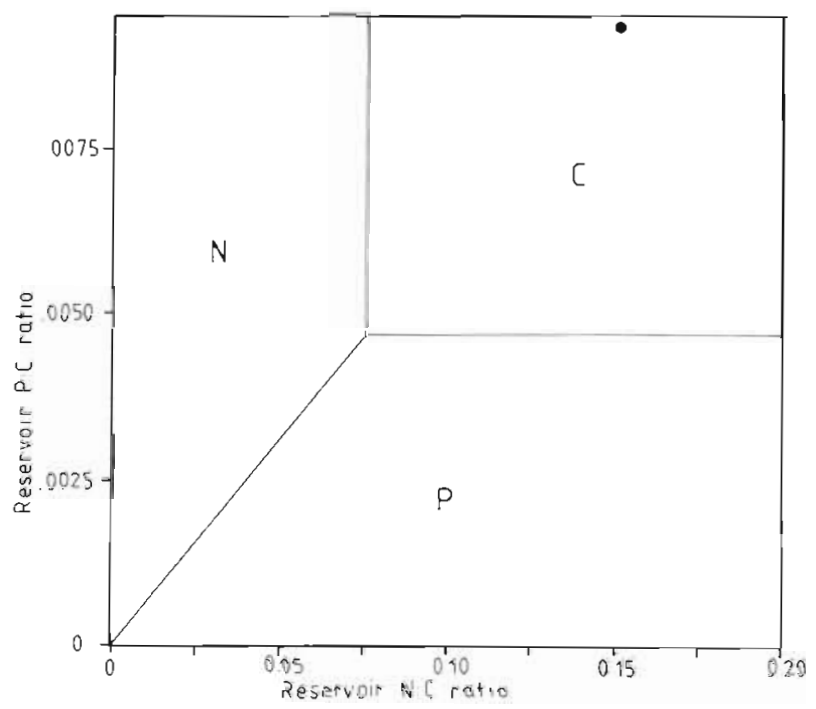

Fig. 1. 'Monod' model. Plane defined by $\mathrm{P}: \mathrm{C}$ and $\mathrm{N}: \mathrm{C}$ ratios of reservoir medium. This plane is sectioned into 3 areas, each characterized by one single nutrient source being depleted from the chemostat culture medium at steady state. Letters denote areas of $\mathrm{C}_{-}, \mathrm{N}$-, and $\mathrm{P}$-limitation, respectively. Point marked in upper right corner corresponds to a Redfield ratio composition of the reservoir medium

Using the plane defined by the axis given by the reservoir $\mathrm{N}: \mathrm{C}$ and $\mathrm{P}: \mathrm{C}$ ratios (subsequently called the N,P plane), 3 distinct, non-overlapping areas of uniquely defined limitations are obtained. The position of the bordering lines between these areas may be deduced from the condition that 2 substrates are depleted simultaneously during bacterial growth: (1) when $C$ is sufficient, $N$ and $P$ will be depleted simultaneously along the line $\mathrm{N}: \mathrm{P}=16: 1$; (2) when $\mathrm{P}$ is sufficient, $\mathrm{C}$ and $\mathrm{N}$ will be depleted simultaneously along the line $N: C=16: 212(=0.075)$; while (3) when $N$ is sufficient, $C$ and $P$ will be depleted simultaneously along the line $\mathrm{P}: \mathrm{C}=1: 212(=0.0047)$. In Fig. 2, the concentrations of N, P and organic $C$ in the cultures at steady state are indicated by isolines in the N. P plane connecting points of equal culture concentrations.

Fig. $1 \& 2$ would equally well describe the stationary phase of hypothetical batch culture experiments with such a model organism. The $\mathrm{N}: \mathrm{C}$ and $\mathrm{P}: \mathrm{C}$ axes would then represent the ratios in the medium at inoculation, and the isolines of Fig. 2 would represent concen- 


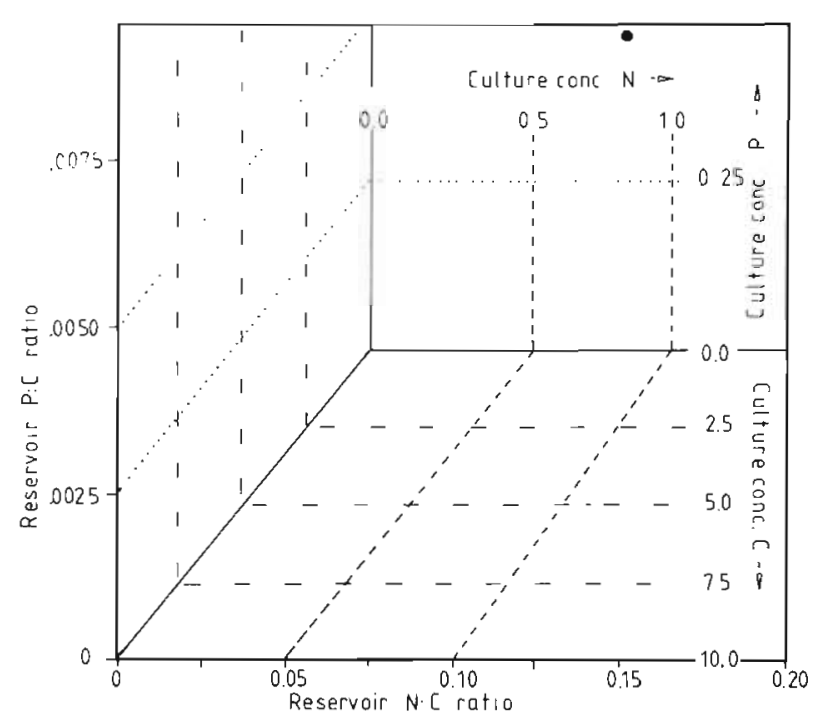

Fig. 2. 'Monod' model. Isolines describing steady-state concentrations of (-.-) $C_{1}(---) N$, and $(\cdots)$ P nutrient in the chemostat culture medium. Concentration of $C$ nutrient in reservoir medium is arbitrarily set to $10 \mu \mathrm{mol} \mathrm{C} ~^{-1}$. Reservoir medium composition corresponding to the Redfield ratio denoted as in Fig. 1

trations in the culture when stationary phase had been reached.

\section{'DROOP' TYPE MODEL}

\section{Model description}

The mathematical formulations of the biological processes used in the 'Droop' type model are summarized in Table 1 , the differential equations are given in Table 2, while the parameter definitions and values for the biological and the chemostat parts of the model are given in Tables $3 \& 4$, respectively. With the need for modelling bacterial $\mathrm{C}$ content, we have chosen a formulation based on cell number, not biomass, as the basic unit, being aware of the warnings given by Droop (Droop 1979). In this type of model, growth depends on a surplus pool of nutrients inside the cells (Eqn 1a, Table 1), not on the outside concentration of limiting nutrient directly. A non-interactive formulation (Droop 1974) is chosen by assuming the growth rate to be controlled only by the cell quota which is closest to its minimum value (Eqn 1b, Table 1). The uptake of a nutrient is assumed to be dependent both on the medium concentration outside the cells, and on the internal concentration of that nutrient in the cell (Eqns 2a, b, c, Table 1). For simplicity, no direct interactions between the uptake of different elements are assumed, though such interactions are well known, and could easily be accommodated in this description. An example would be the dependence of mineral nu-
Table 1. Mathematical description of biological processes in the 'Droop' type model. For definitions and values of parameters see Tables $2,3 \& 4$

Specific growth rate for cell number $B$ :

$\mu=\mu^{\operatorname{nndx}} \cdot(1-\mathrm{f})$

where

$f=$ maximum of $\frac{Q_{C}^{m i n}}{Q_{C}}, \frac{Q_{N}^{m}}{Q_{N}}$, or $\frac{Q_{p}^{\min }}{Q_{P}}$

and

$$
\begin{aligned}
& Q_{C}=\frac{B_{C}}{B} \\
& Q_{N}=\frac{B_{N}}{B} \\
& Q_{P}=\frac{B_{P}}{B}
\end{aligned}
$$

Specific uptake rates of $C, N$, and $P$ :

$$
\begin{aligned}
& V_{C}=v_{C}^{\max } \cdot\left(\frac{Q_{C}^{\text {max }}-Q_{C}}{Q_{C}^{\text {max }}-Q_{C}^{\text {mix }}}\right) \cdot \frac{C}{K_{C}+C} \\
& V_{N}=v_{N}^{\text {max }} \cdot\left(\frac{Q_{N}^{\text {max }}-Q_{N}}{Q_{N}^{\text {max }}-Q_{N}^{\text {min }}}\right) \cdot \frac{N}{K_{N}+N} \\
& V_{P}=v_{P}^{\text {max }} \cdot\left(\frac{Q_{P}^{\text {max }}-Q_{P}}{Q_{P}^{\text {max }}-Q_{P}^{\text {mins }}}\right) \cdot \frac{P}{K_{P}+P}
\end{aligned}
$$

Specific respiration:

$$
\begin{aligned}
& R=\rho^{g} \cdot Q_{C} \cdot \mu+\rho^{r}\left(Q_{C}-Q_{C}^{m i n}\right) \\
& \text { 'growth' 'maintenance }
\end{aligned}
$$

trient uptake on the availability of organic carbon for energy production (Harold \& Spitz 1975).

We have chosen parameters of the model corresponding to a Redfield ratio between the minimum cell quotas of $\mathrm{C}, \mathrm{N}$, and $\mathrm{P}$ (Table 3). With the formulation chosen for the control of uptake rate by internal cell quotas (Eqns 2a, b, c, Table 1), there is also an upper limit to the cell quotas. These are chosen to be twice as large as the minimum quotas (Table 3). Maximum uptake rates are chosen so that, at a constant maximum velocity, $0.5 \mathrm{~h}$ would be needed to take up an amount equal to the minimum quotas (Table 3 ).

It has been shown that 'Droop' type models may be used to fit experimental results of bacterial growth in chemostats limited by mineral nutrients (Nyholm 1976). Organic carbon, however, is needed not only for biomass production but also for energy production, and the model has to be extended in some way to incorporate the bacterial respiration of parts of the carbon source.

As a first approximation, we wanted a model that could give a description of the following observed features of bacterial respiration: (1) the existence of an energy consumption independent of growth (Marr et al. 1963); (2) the shut-down of all metabolism to undetectable levels in cases of extreme carbon limitation 
Table 2. State variables and differential equations of 'Droop' model. For definitions and values of parameters see Tables 3 \& 4

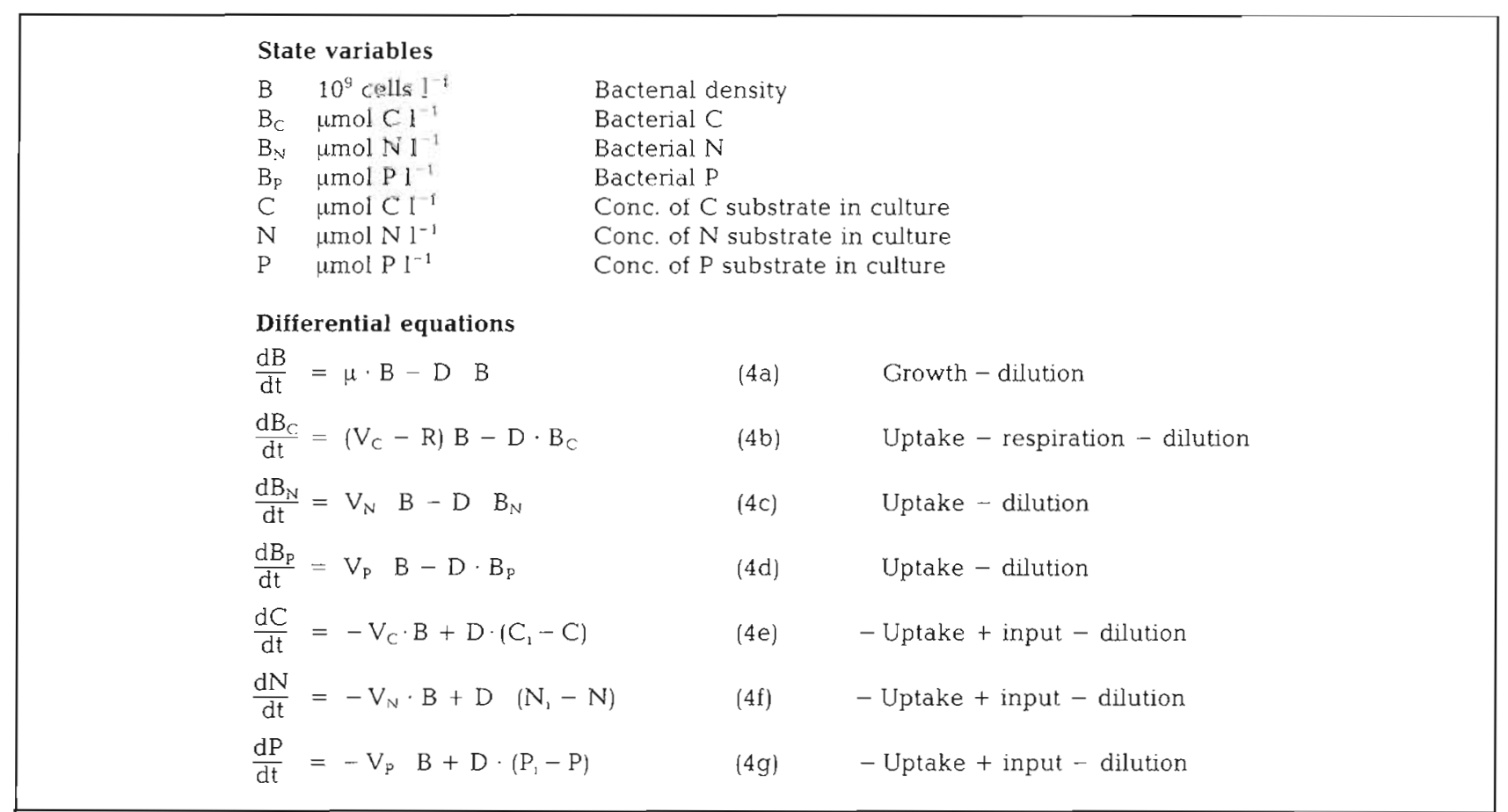

Table 3. Biological parameters used in 'Droop' model. Symbols, values, and units

\begin{tabular}{|c|c|c|}
\hline$\mu^{\max }$ & $h^{-1}$ & Maximum specific growth rate \\
\hline$\rho^{g}$ & Dimensionless & $\begin{array}{l}\text { Proportionality factor between carbon incorporated and } \\
\text { respired for growth }\end{array}$ \\
\hline$\rho^{r}$ & Dimensionless & Fraction of surplus carbon respired $\mathrm{h}^{-1}$ \\
\hline$\delta$ & Dimensionless & $\begin{array}{l}\text { Proportionality constant of decoupling. Value corresponds to } \\
\text { increase in growth-independent respiration when } Q_{\mathrm{P}}=\mathrm{Q}_{\mathrm{P}}^{\min }\end{array}$ \\
\hline$v_{c}^{\max }$ & 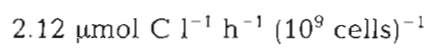 & Maximum specific uptake rate $\mathrm{C}$ \\
\hline$v_{N}^{\operatorname{man}}$ & 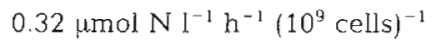 & Maximum specific uptake rate $\mathrm{N}$ \\
\hline$v_{P}^{\text {miax }}$ & $0.02 \mu \mathrm{mol} \mathrm{P} 1^{-1} \mathrm{~h}^{-1}\left(10^{9} \text { cells }\right)^{-1}$ & Maximum specific uptake rate $\mathrm{P}$ \\
\hline $\mathrm{K}_{\mathrm{C}}$ & $1.0 \mu \mathrm{mol} \mathrm{C} \mathrm{^{-1 }}$ & Half-saturation const. uptake C \\
\hline $\mathrm{K}_{\mathrm{N}}$ & $0.1 \mu \mathrm{mol} \mathrm{N}{ }^{-1}$ & Half-saturation const. uptake $\mathrm{N}$ \\
\hline$K_{p}$ & $0.01 \mu \mathrm{mol} \mathrm{P} 1^{-1}$ & Half-saturation const. uptake $\mathrm{P}$ \\
\hline$Q_{C}^{\min }$ & $1.06 \mu \mathrm{mol} \mathrm{C}\left(10^{9} \text { cells }\right)^{-1}$ & Minimum cell quota $C$ \\
\hline$Q_{N}^{\min }$ & $0.16 \mu \mathrm{mol} \mathrm{N}\left(10^{9} \text { cells }\right)^{-1}$ & Minimum cell quota $\mathrm{N}$ \\
\hline$Q_{p}^{\min }$ & $0.01 \mu \mathrm{mol} \mathrm{P}\left(10^{9} \text { cells }\right)^{-1}$ & Minimum cell quota $\mathrm{P}$ \\
\hline$Q_{C}^{\max }$ & 2.12 umol C $\left(10^{9} \text { cells }\right)^{-1}$ & Maximum cell quota $C$ \\
\hline$Q_{N}^{\max }$ & $0.32 \mu \mathrm{mol} \mathrm{N}\left(10^{9} \text { cells }\right)^{-1}$ & Maximum cell quota $N$ \\
\hline$Q_{\mathrm{p}}^{\max }$ & $0.02 \mu \mathrm{mol} \mathrm{P}\left(10^{9} \text { cells }\right)^{-1}$ & Maximum cell quota $P$ \\
\hline
\end{tabular}

(Amy et al. 1983); and (3) an increase in respiration coefficient when going from a carbon-limited to a mineral-nutrient-limited situation (Tempest et al. 1985). In our model, this is accomplished by regarding respiration as a process removing carbon from the internal pool of $\mathrm{C}$ (Eqn $4 \mathrm{~b}$, Table 2). The specific rate $\mathrm{R}$ of this removal is chosen so as to contain one term proportional to the production rate of new cell carbon, and one term proportional to the 'surplus' amount of carbon cell per cell [i.e. proportional to $\left.\left(Q_{c}-Q_{C}{ }^{\min }\right)\right]$ 
Table 4 . Chemostat parameters, symbols and units

\begin{tabular}{|lll|}
\hline $\mathrm{D}$ & $\mathrm{h}^{-1}$ & Dilution rate \\
$\mathrm{C}_{1}$ & $\mu \mathrm{mol} \mathrm{l} 1$ & Conc. of C substrate in reservoir \\
$\mathrm{N}_{1}$ & $\mu \mathrm{mol} \mathrm{l}^{1}$ & Conc. of $N$ substrate in reservoir \\
$\mathrm{P}_{1}$ & $\mu \mathrm{mol} \mathrm{I}^{-1}$ & Conc. of P substrate in reservoir \\
\hline
\end{tabular}

(Eqn 3a, Table 1). In a situation limited by mineral nutrients, there will be a large internal pool of surplus $C$, and hence a relatively large growth-independent respiration. In a carbon-limited situation, however, the amount of surplus $\mathrm{C}$ will approach zero as growth rate approaches zero, and all metabolism will be shut off.

\section{Model behavior}

\section{Areas of different limitations}

The behavior of this model in chemostat cultures was explored using simulation technique. Numerical solutions were obtained using a 4 th-order Runge-Kutta algorithm with variable time increments. Programs were written in Turbo Pascal and run on an Olivetti M21 personal computer equipped with an 8087 mathematical coprocessor. Fig. 3 summarizes the results of such simulations for variable concentrations of $\mathrm{N}$ and $\mathrm{P}$ in the reservoir medium. Reservoir concentration of organic C was kept constant for all simulations, the numerical value arbitrarily set to $10 \mu \mathrm{molCl} l^{-1}$.

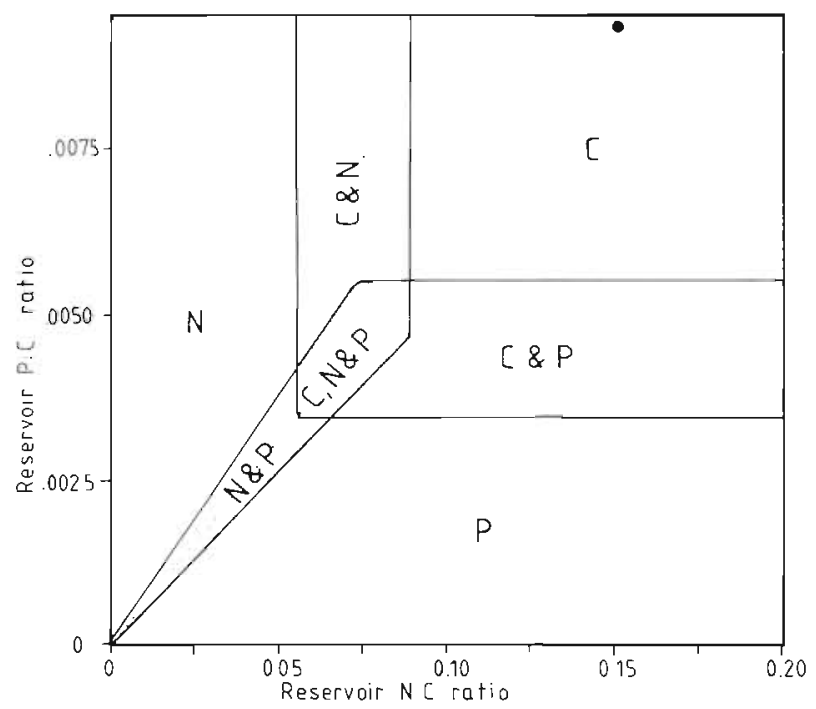

Fig. 3. 'Droop' model. Areas of nutrient depletion in the chemostat culture medium at steady state with dilution rate $\mathrm{D}=0.1 \mathrm{~h}^{-1}$. Letters denote nutrients being depleted. Shaded area corresponds to depletion of all 3 nutrients. Demarcation lines of the 'Monod' model indicated by dotted lines. Medium composition corresponding to the Redfield ratio indicated as in Fig. 1
Due to the flexibility in bacterial composition and respiration introduced in this type of model, the lines dividing the N, P plane are all split as shown in Fig. 3. As a consequence, the number of distinct areas increases from 3 to 7 , each area characterized by depletion of 1, 2, or all 3 nutrients from the cultures. Although the growth in bacterial numbers in this model is uniquely limited by the cell quota of one single substrate (Eqn 1, Table 1), the medium may be depleted also for one or both of the other nutrients. The cause of this is the variability in biomass composition. One substrate is thus controlling growth in cell numbers, while 1, 2 or all 3 may be controlling biomass composition. Whether or not this should be regarded as a violation of Liebig's law seems to be a matter of definition.

In this type of model, the maximum growth rate during balanced, 'unlimited' growth is smaller than the $\mu^{\text {max }}$-parameter of Eqn 1 . Its value may be computed using the condition that uptake rate of a nutrient must balance dilution of the amount per cell due to growth in cell number and, for the carbon source, it must also balance the consumption of cell carbon for energy production. With the parameter values chosen, balanced exponential growth would be controlled by the uptake rate for organic carbon. When growth in cell number is reduced due to the limitation by one nutrient, the diluting effect of growth on the cell quotas decreases. The cell quotas of the 2 other nutrients will then increase until the negative effect of increased cell quota on uptake results in a new balance between uptake and dilution/consumption. The model thus provides a phenomenological description of general concepts such as proposed by Dawes \& Senior (1973) that storage of carbon reserve materials should be expected when growth is limited by some other factor than the carbon/energy source.

Since one would expect carbon content to be reflected in cell volumes, one would from this model expect to observe cells larger at high than at low growth rates when carbon is limiting. Likewise, mineral nutrient limitation would be expected to result in larger cells than carbon limitation. This general trend seems to be in accordance with observations (Ecker \& Schaechter 1963). The observations of Maaløe \& Kjeldgaard (1966) that fast-growing bacteria contain more RNA, DNA, and protein than slow-growing bacteria, would also be in general agreement with the model's prediction of increased cell quotas of $\mathrm{N}$ and $\mathrm{P}$ at rapid growth rates.

If the chemostat dilution rate is close to the maximum obtainable growth rate, the change in internal cell quotas between those obtained during free exponential growth and those obtained at steady state of the chemostat will be small. Likewise, if the dilution rate is 
small, the change will be great. The effect of this is demonstrated in Fig. 4 which is similar to Fig. 3, except that dilution rate is decreased from 0.1 to $0.01 \mathrm{~h}^{-1}$. Note how the shaded area expands with decreasing $\mathrm{D}$, demonstrating how the range of medium

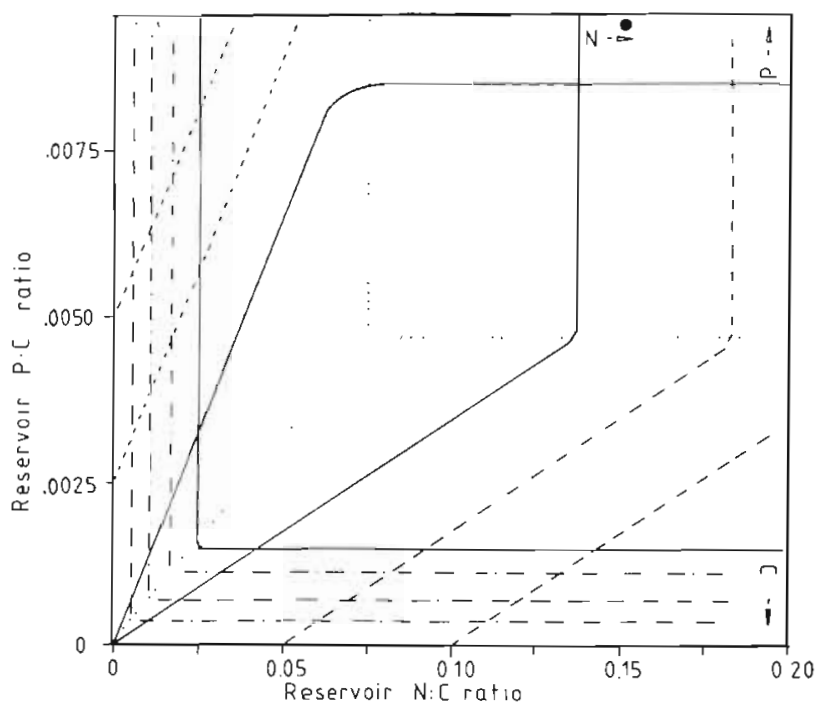

Fig. 4. 'Droop' model. Areas of nutrient depletion in chemostrat culture medium at steady state with dilution rate $\mathrm{D}=$ $0.01 \mathrm{~h}^{-1}$. Area where all 3 nutrients are depleted shaded as in Fig. 3. Isolines of steady-state nutrient concentrations in culture medium denoted as in Fig. 2. Reservoir medium composition corresponding to the Redfield ratio indicated as in Fig. 1

$\mathrm{N}: \mathrm{C}$ and $\mathrm{N}: \mathrm{P}$ ratios for which all 3 nutrients are exhausted will expand with decreasing growth rate. Along the coordinate axes of Fig. 4 there is a 'border' where the medium is not depleted of the $C$ nutrient. Due to the growth-rate-independent consumption of organic carbon, this 'border' will disappear as D approaches zero. As a result, the areas of pure $\mathrm{N}$ and pure P limitation also disappear.

For completeness, the effect of reservoir N:C and $P: C$ ratios on steady-state bacterial biomass composition and respiration coefficient is shown in Fig. 5.

\section{Respiration}

Pirt (1982) has suggested a mathematical model for bacterial consumption of energy, fitting situations of both carbon/energy and mineral nutrient limitation. Fig. 6 of this paper corresponds to his Fig. 2, both describing data obtained by Neijssel \& Tempest (1976). To be directly comparable to model output, the scale on the ordinate axis of Fig. 6 is recomputed from the original specific oxygen consumption rate in units $\mathrm{mmol} \mathrm{O}_{2}(\mathrm{~g} \text { dry } \mathrm{wt})^{-1} \mathrm{~h}^{-1}$ to the equivalent 'specific

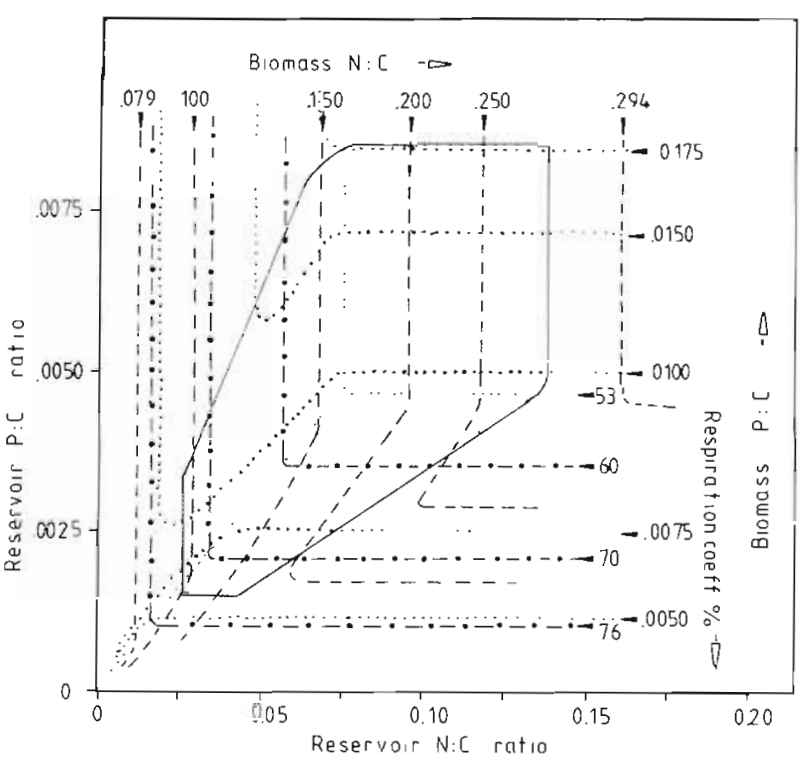

Fig. 5. 'Droop' model. Isolines describing (-.-) respiration coefficient, $(--)$ biomass $\mathrm{N}: \mathrm{C}$, and $(\cdots)$ biomass $\mathrm{P}: \mathrm{C}$ ratios for the same simulations as used to generate Fig. 4.

Shaded area as in Fig. 4

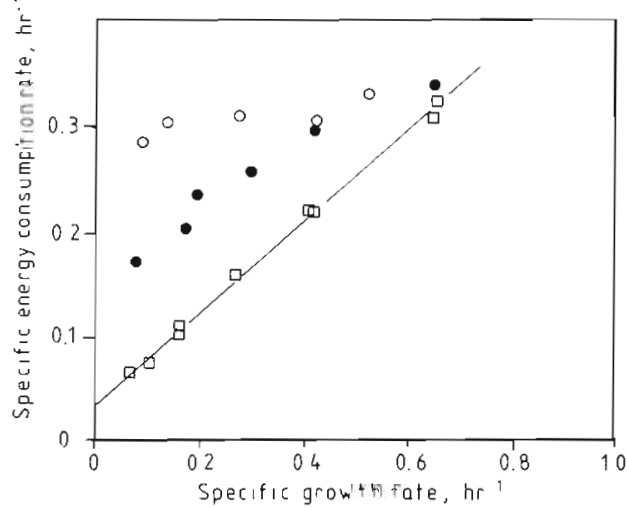

Fig. 6. Experimental data of specific energy consumption rate from Neijssel \& Tempest (1976). (口) Glucose-, (•) ammonia-, and $(O)$ phosphate-Limited cultures. Corresponds to Fig. 5 of Neijssel \& Tempest and to Fig. 2 of Pirt (1982). The positions in the $\mathrm{N}, \mathrm{P}$ plane of the respective reservoir media used by Neijssel \& Tempest are indicated in Fig. 9

energy consumption rate' in units mol respired $\mathrm{C}$ (mol biomass $\mathrm{C}^{-1} \mathrm{~h}^{-1}$, by assuming a $1: 1$ ratio between $\mathrm{C}$ consumed and $\mathrm{O}_{2}$ consumed, and a $50 \%$ carbon content in biomass.

We have fitted a straight line to the data from glucose-limited chemostats of Fig. 6. Pirt's model assumes that straight lines should be fitted also to the data points from mineral-nutrient-limited cultures, and that these may be extrapolated to zero specific growth rate to give the 'maintenance' requirement of the cells. If the mathematical extrapolation is supposed to reflect a biological reality, and if no additional assumptions are 
made, this particular detail creates an inconsistency: if there is a growth-rate-independent consumption of the energy source, while consumption of mineral nutrient approaches zero with decreasing growth rate, the carbon:mineral nutrient ratio in substrate consumption must approach infinity. For a sufficiently low growth rate, the carbon:mineral nutrient ratio of consumption will surpass that of any medium. This is incompatible with an assumption of growth limited by a mineral nutrient.

In the model presented above, this inconsistency disappears. As is demonstrated by the sequence of Fig. $3 \& 4$, and the discussion above, any mineralnutrient-limited culture (positioned close to one of the axes of the $\mathrm{N}, \mathrm{P}$ plane) will undergo a transition from pure mineral nutrient limitation to mixed carbon and mineral nutrient limitation as D decreases.

Fig. 7 gives the form of the curves predicted by the present model. Mineral nutrient limitations (curves marked 1, 2, 4, 6 and 7) give curves above the straight

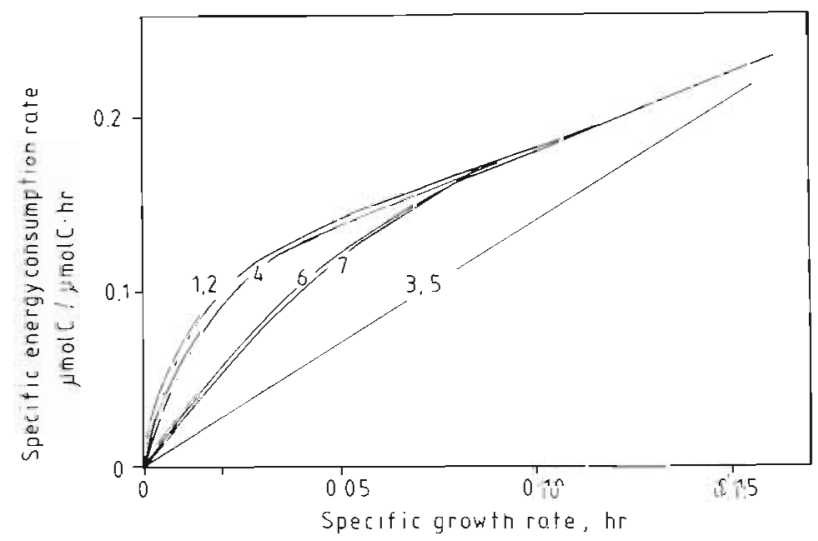

Fig. 7. 'Droop' model. Variation with specific growth rate of specific rate of carbon consumption for respiration. To amplify the difference between carbon and mineral nutrient limitation, the fraction of surplus carbon being respired $h^{-1}$ $\left(\rho^{r}\right)$ is set to 0.2 as opposed to 0.05 in the simulations used to generate Fig. 4 \& 5. Each curve corresponds to a fixed composition of the reservoir medium. Numbers on the curves correspond to the respective reservoir medium compositions as given in Fig. 9

line of pure glucose limitation (curves 3 and 5). As growth rate approaches zero, however, all curves approach the origin; they do not extrapolate to a 'maintenance' energy at zero growth rate. We have shown above that the line of demarcation in the N, P plane between pure mineral nutrient limitation and mixed carbon/mineral nutrient limitation moves towards the axes of the $\mathrm{N}, \mathrm{P}$ plane with decreasing growth rate (Fig. $3 \& 4$ ). The growth rate at which the curves of Fig. 7 deflect toward the origin is therefore dependent upon the position in the N:P plane, i.e. on the $N: C$ and $P: C$ ratios of the reservoir medium. This effect is demonstrated by the form of curves 1,2 , and 4 of Fig. 7, as opposed to curves 6 and 7 . In practical work, a deflection would therefore only be observable in cultures with intermediate reservoir $\mathrm{N}: \mathrm{C}$ and/or $\mathrm{P}: \mathrm{C}$ ratios. The positions in the $\mathrm{N}, \mathrm{P}$ plane of the glucose-, ammonia-, and phosphate-limited cultures of Neijssel \& Tempest (1976) are included in Fig. 9.

There are 2 distinct features of the data given in Fig. 6 not explainable by the model in its present form: (1) the straight line fitted to the observations from carbon-limited cultures extrapolate to give a small energy consumption at zero growth rate; and (2) energy consumption under phosphate limitation clearly exceeds that under ammonium limitation. These features may, however, be easily incorporated. The mathematical formulations used are given in Table 5 . With this formulation, an energy consumption

Table 5. Modifications of the 'Droop' model given in Tables 1 , 2, $3 \& 4$ as used in the simulations that generated Fig. 8

$$
\begin{aligned}
& \text { Eqn (1b) replaced by: } \\
& f=\text { maximum of } \frac{Q_{C}^{g}}{Q_{C}}, \frac{Q_{N}^{m i n}}{Q_{N}} \text {, or } \frac{Q_{P}^{m i n}}{Q_{P}} \text { if } Q_{C}>Q_{C}^{g} \\
& \text { and } \\
& \mathrm{t}=1 \text { if } \mathrm{Q}_{\mathrm{C}}<\mathrm{Q}_{\mathrm{C}}^{\mathrm{g}} \\
& \text { 'Maintenance' term of Eqn (3a) replaced by: } \\
& \rho^{r} \quad\left(Q_{C}-Q_{C}^{\min }\right)\left(1+\delta \cdot\left(\frac{Q_{p}^{\max }-Q_{p}}{Q_{p}^{\max }-Q_{p}^{\min }}\right)\right. \\
& Q_{C}^{g}=1.11 \mu \mathrm{mol} C\left(10^{9} \text { cells }\right)^{-1} \text { Cell quota of } C \text { at which } \\
& \delta=2.0 \text { (dimensionless) 'Decoupling' factor of } \\
& \text { phosphate starvation } \\
& \rho^{\mathrm{r}}=0.20 \quad \text { As in Table } 3
\end{aligned}
$$

at zero growth rate may be obtained by introducing a slightly higher minimum carbon cell quota for growth than the one used for respiration (Eqn 1f, Table 5). Such a model would be in accordance with the observations of McGrew \& Malette (1965) of uptake, but no net growth, when glucose was fed at a slow rate to batch cultures of Escherichia coli. Introducing this modification, any apparent contradiction between an energy consumption when chemostat observations are extrapolated to zero growth rate, and the observation of living cells with undetectable respiration in carbonstarved batch systems, is resolved.

The increased energy consumption under phosphate limitation may be modelled by assuming the 'maintenance' term of respiration to increase with decreasing phosphorus cell quota (Eqn 3b, Table 5). The model does not explicitly require any assumption as to the 
biological background for this relation. Neijssel \& Tempest (1975) suggested the possibility of a partial decoupling of respiration from ATP generation as a result of P-starvation. This would provide one possible biological justification for the proposed model. The effects of these modifications are shown in Fig. 8. The specific energy consumption is now higher for extreme P limitation (curve 4, Fig. 8) than for extreme $N$ limitation (curve 2, Fig. 8). All curves approach the same positive intercept with the ordinate axis as growth rate approaches zero.

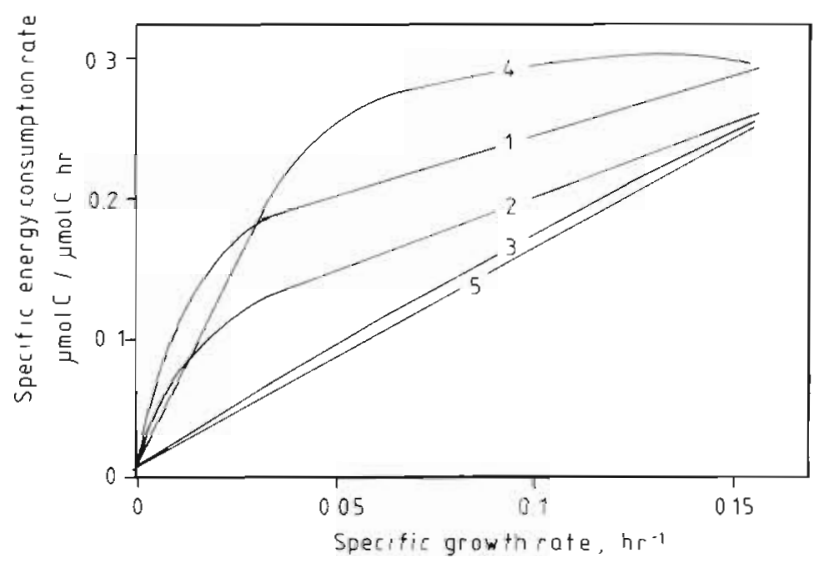

Fig. 8. 'Droop' model with refinements given in Table 5, corresponding to Fig. 4. Line 4 corresponds to the most extreme $\mathrm{P}$ limitation, Line 2 to the most extreme $\mathrm{N}$ limitation and Line 5 to the most extreme $\mathrm{C}$ limitation. Numbers on lines correspond to the respective reservoir medium compositions as given in Fig. 9

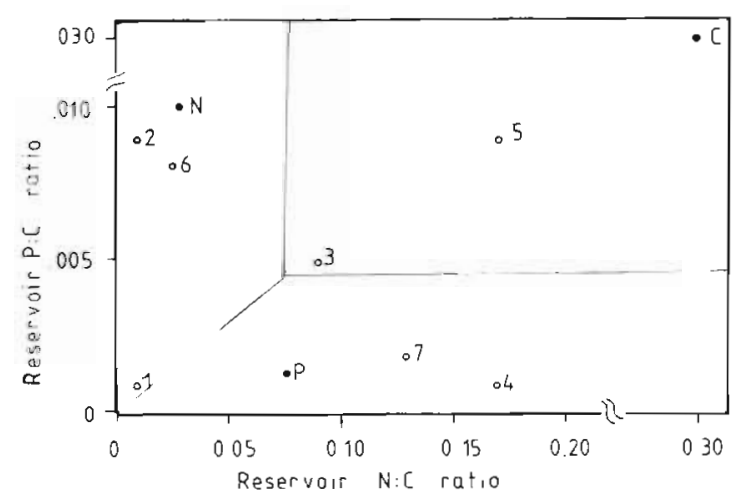

Fig. 9. Reservoir medium compositions used for the experimental and simulated curves of Fig. $6,7 \& 8$. Numbers correspond to those on the respective theoretical curves in Fig. 7 \& 8 ; letters correspond to the (C) glucose-, (N) $\mathrm{NH}_{4}{ }^{-}$, and (P) $\mathrm{PO}_{4}$-limited cultures of Neijssel \& Tempest (1976) shown in Fig. 6

\section{Mineral nutrient consumption}

With the extensions in the model proposed above, the effect of dilution rate on the area in the $N, P$ plane where both $N, P$ are depleted will be slightly more complex. In a situation of pure carbon limitation, an increasing fraction of the carbon will be lost by respiration. The need for carbon will then increase relative to the need for mineral nutrients, and the area of pure $C$ limitation in the N, P plane will expand towards the axes as $\mathrm{D}$ becomes sufficiently small.

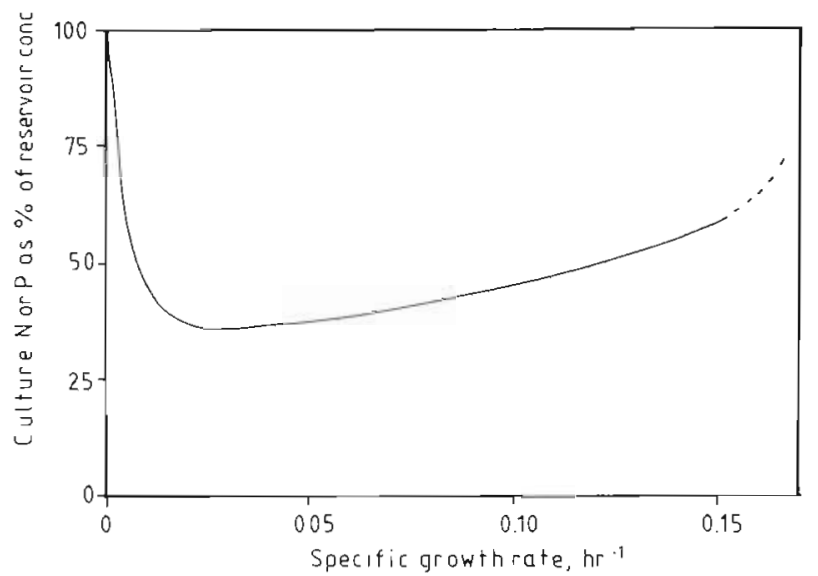

Fig. 10. 'Droop' model with extensions given in Table 5. Culture concentration of mineral nutrients as a function of growth rate for a Redfield ratio composition of the reservoir medium. With reservations given in text, the ordinate axis may be regarded as \% of mineral nutrients remineralized from a complex substrate with a Redfield ratio composition

To illustrate the consumption of mineral nutrients in a mainly $C$-limited situation, we have chosen the point in the $N, P$ plane corresponding to a Redfield ratio composition of the reservoir medium. This point is marked in Fig. 1, 2, 3 \& 4. In Fig. 10 is shown the steady-state culture concentrations of mineral nutrients (with parameters chosen, results are identical for $\mathrm{N}$ and $\mathrm{P}$ ) as a function of dilution rate $\mathrm{D}$. As $\mathrm{D}$ decreases from the maximum obtainable growth rate, the culture concentration of mineral nutrients decreases due to the increase of the shaded area as shown by the sequence Fig. 3 to 4 . At a sufficiently low dilution rate, however, this is counteracted by the increase in the area of pure $C$ limitation, i.e. as D approaches zero the concentrations of free mineral nutrients in the culture increase due to the large respiration loss of carbon.

\section{DISCUSSION}

Analysis of bacterial growth in chemostats has traditionally been analysed by 'Monod' type models, assuming growth rate to be directly dependent upon medium concentration. Experimentally observed. changes in yield with dilution rate have been described mathematically as yield being an explicit 
function of growth rate (e.g. Veldkamp 1976). Since a chemostat at equilibrium does not provide information on cause-and-effect relations, a model assuming yield to be a function of growth rate may predict the same equilibrium as a model assuming growth rate to be a function of biomass composition. The 'Monod' type formulation may therefore be sufficient for many purposes. It is also convenient since only one state variable (cell density or biomass) is required to describe the bacteria, and the equilibria are usually amenable to analytical investigation

A 'Droop' type formulation as used here requires more state variables, in our case $4\left(B, B_{C}, B_{N}\right.$, and $B_{p}$; Table 2), and analysis is more cumbersome. For the analysis presented, we have resorted to numerical solution of the differential equations (Table 2). In our opinion, however, the 'Droop' type formulation allows an easier incorporation of biologically plausible concepts. The importance of this is exemplified in the above analysis of how energy requirement varies with both growth rate and medium composition. The 'Droop' type formulation also seems more convenient for incorporation of refinements such as an energy requirement of mineral nutrient uptake. Some relevant extensions, such as the experimentally observed large variation in energy requirement with type of carbon source (Hempfling \& Mainzer 1975) would, however, require more extensive modification.

Various experimental data supports the proposed model. The applicability of 'Droop' type models as descriptions of bacteria in steady-state chemostats limited by one mineral nutrient was demonstrated by Nyholm (1976). The qualitative applicability of the model to published measurements of energy utilization under various growth conditions is demonstrated above. In a parallel study, Martinussen \& Thingstad (unpubl.) have demonstrated how the pattern of nutrient depletion from chemostat and batch cultures to a large extent follows the predictions of this model. They also apply the model to transient situations such as growth and nutrient consumption in batch cultures, and phosphate uptake in P-starved cultures. This apparently broad applicability of the model does of course not imply that the specific form chosen for the equations could not be improved.

Our analysis has considered steady-state situations only. As is well known from algal physiology, the 'Droop' type formulation also provides a conceptual framework for experiments studying transient situations such as 'shift-up' experiments where mineral nutrients are supplied to mineral-nutrient-deficient cells (e.g. Parslow et al. 1984). The outcome of algalalgal competition experiments in fluctuating environments has been shown to depend upon the ability to store mineral nutrients (Sakshaug \& Olsen 1986).
'Monod' type formulations of bacterial growth would not provide a sufficient conceptual framework for analysis of algal-bacterial competition experiments of this kind.

We have hesitated to use the term 'maintenance metabolism for the respiration term not explicitly dependent upon growth rate (Eqn $3 b$, Table 5), since it was not a priori obvious to us whether such a terminology would be reconcilable with traditional use of this term (e.g. Stouthammer 1977). However, with the connection between our formulation and that of Pirt demonstrated through Fig. 6, 7 \& 8, a use of the term 'maintenance' for this part of our model does not seem to conflict seriously with present terminology. Our suggestion is therefore that 'maintenance' should be used for terms equivalent to our Eqn (3b). There are, however, weaknesses with this terminology. The mathematical formulation of Eqn (3b) describes how surplus carbon is consumed, not the purpose for which the energy will be used. The 'maintenance' defined in this way may therefore well contain components which more appropriately could be called 'waste' metabolism. This ambiguity is, however, inherent also in present terminology, and is apparently the background for 'the general acceptance that "maintenance" is a misnomer when applied to energy-sufficient cultures' (Neijssel \& Tempest 1976). Another possible terminology would be 'growth-independent' metabolism. Though formally correct, the latter terminology may, however, cause confusion. Although the term is by definition not an explicit function of growth rate, it is dependent upon cell quotas which will change with growth rate. Confusion could therefore arise from the fact that a 'growth-independent' metabolism would be implicitly growth-rate dependent.

Defined as a carbon-consuming term of the type given in Eqn (3b), an unsatisfactory explicit variation in 'maintenance' with growth rate as in the description proposed by Pirt (1982), is avoided. In the form suggested the terminology of a 'maintenance' metabolism seems applicable to situations of different growth limitations as well as to situations of different growth rate.

The simple 'Monod' model with constant yield first introduced would predict a rigid stoichiometric coupling of $\mathrm{C}, \mathrm{N}$, and $\mathrm{P}$ transport through the bacterial link in the food web. The use of a 'Droop' formulation introduces a 'slack' in this coupling. According to the model, this 'slack' decreases as growth rate increases towards maximum growth rate since, as shown, the results of the 'Droop' formulation then approach those of the 'Monod' model (Fig. 5, 3, \& 1).

Since respiration varies both with growth rate and with type of nutrient limitation, environmental conditions will determine the efficiency by which carbon is transferred through bacteria to bacterial predators and 
thus is made available to higher trophic levels in the food chain (Azam et al. 1983).

Our analysis has been based upon the assumption of chemically and physically independent $C, N$, and $P$ nutrient sources. This assumption is not valid for bacterial growth on a complex substrate such as dead aIgal cells. If, however, we assume that both bacterial respiration and bacterial biomass composition are independent of any chemical or physical coupling between nutrient components, the analysis may be directly extended to growth on such complex substrates. In a situation where the substrate contains mineral nutrients in excess of the amount incorporated in bacterial biomass, these nutrients would have to be excreted, i.e. bacteria would function as remineralizers. This is exemplified by the point marked in $N, P$ planes of Fig. 1, 2, $3 \& 4$, denoting a substrate having a $C: N: P$ composition equal to the Redfield ratio. In our 'Monod' type model (Fig. 1 \& 2), the bacteria will remineralize $50 \%$ of the $\mathrm{N}$ and $\mathrm{P}$ in such a substrate, since $50 \%$ of the carbon is assumed to be lost by respiration and the bacterial biomass composition is assumed to be equal to that of the Redfield ratio. As was shown in Fig. 10, the remineralization predicted from the extended Droop model (Table 5) will be growth-rate dependent in a quite complicated manner. The relevance of this to the degradation of particulate manner must be judged with some care, however, since the growth rate variation in Fig. 10 is caused by variation in the supply rate of nutrients. This may be a poor model for bacterial growth on particulate matter. If and when the 'Redfield' point of Fig. 4 is encompassed by the shaded area of $\mathrm{N}$ and $\mathrm{P}$ depletion, is of course dependent upon the parameters of the model.

Our choice of parameters is based on the sole cricerion of a bacterial biomass composition fitting the Redfield ratio. Recomputation of the general values of elemental composition of bacterial biomass given by Schlegel (1969) gives $N$ : C ratios in the range 0.16 to 0.29 and $P: C$ ratios in the range 0.014 to 0.052 , as opposed to the Redfield ratios of 0.15 and 0.009 , respectively. The large $N$, and especially the large $P$, content of bacteria would thus suggest that remineralization is less than indicated by our choice of parameters. This may of course be counteracted by an eventual increase of the parameters $\rho^{g}$ and $\rho^{r}$ (Table 3) regulating respiratory loss of carbon. In a situation where an algal bloom collapses due to mineral nutrient limitation, the algal biomass would be suspected to have low N:C and/or P:C ratios. This also would lead to less probability of bacterial remineralization than suggested by our choice of examples.

The model suggests that a relatively complex pattern of interactions may regulate the role of bacteria as mineral nutrient consumers of remineralizers. If this is correct, categoric statements as to whether bacteria act as remineralizers or consumers of mineral nutrients in marine ecosystems would seem to be of limited value.

Acknowledgements. This work was supported by the Norwegian Research Program for Marine Arctic Ecology (PROMARE). I thank Prof. I. Dundas for valuable help with the manuscript and for originally pointing out that inconsistencies might exist in the contemporary concept of bacterial 'maintenance' metabolism.

\section{LITERATURE CITED}

Amy, P. S., Pauling, C., Morita, R. Y. (1983). Starvationsurvival processes of a marine vibrio. Appl. environ. Microbiol. 45: 1041-1048

Azam, F., Fenchel, T., Field, J. G., Gray, J. S., Meyer-Reil, L. A., Thingstad, T. F. (1983). The ecological role of water column microbes in the sea. Mar. Ecol. Prog. Ser. 10: $257-263$

Dawes, E. A., Senior, P. J. (1973). The role and regulation of energy reserve polymers in micro-organisms. Adv. microbial. Phys. 10: 135-266

Droop, M. R. (1974). The nutrient status of algal cells in continuous culture. J. mar. biol. Ass. U.K. 54: 825-855

Droop, M. R. (1979). On the definition of $X$ and $Q$ in the cell quota model. J. exp. mar. Biol. Ecol. 39: 203

Ecker, R. E., Schaechter, M. (1963). Bacterial growth under conditions of limited nutrition. Ann. N.Y. Acad. Sci. 102: 549-563

Harold, F. M., Spitz, E. (1975). Accumulation of arsenate, phosphate, and aspartate by Streptococcus faecalis. J. Bacteriol. 122: 266-277

Hempfling, W. P., Mainzer, S. E. (1975). Effects of varying the carbon source limiting growth on yield and maintenance characteristics of Escherichia coli in continuous culture. J. Bacteriol. 123: 1076-1087

Herbert, D. (1961). The chemical composition of micro-organisms as a function of their environment. In: Meynell, $G$. $G$., Gooder, H. (ed.) Eleventh Symposium Soc. Gen. Microbiol., Cambridge University Press, Cambridge, p. $391-416$

Johannes, R. E. (1968). Nutrient regeneration in lakes and oceans. In: Droop, M. R., Ferguson, E. J. (ed.) Adv. Microb. Sea 1: 203-213

Mann, K. H. (1982). The ecology of coastal waters. A system approach. Blackwell, Oxford

Marr, A. G., Nilson, E. H., Clark, D. J. (1963). The maintenance requirement of Escherichia coli. Ann. N.Y Acad. Sci. 102: $536-548$

McGrew, S. B., Malette, M. F. (1965). Maintenance of Escherichia coli and the assimilation of glucose. Nature, Lond. 208: 1096-1097

Monod, J. (1942). Recherches sur la croissance des cultures bacteriennes. Dr. diss. Herman \& Cie, Paris

Maaløe, O., Kjeldgaard, N. (1966). Control of macromolecular synthesis. Benjamin, New York

Neijssel, O. M., Tempest, D. W. (1975). The regulation of carbohydrate metabolism in Klebsiella aerogenes NCTC 418 organisms, growing in chemostat cultures. Arch. Microbiol. 106: 251-258

Neijssel, O. M., Tempest, D. W. (1976). Bioenergetic aspects of aerobic growth of Klebsiella aerogenes NCTC 418 in 
carbon-limited and carbon-sufficient chemostat culture. Arch. Microbiol. 107: 215-221

Nyholm, N. (1976). A mathematical model for microbial growth under limitation by conservative substrates. Biotechnol. Bioeng. 18: 1043-1056

Parslow, J. S., Harrison, P. J., Thompson, P. A. (1984). Saturated uptake kinetics: transient response of the marine diatom Thalassiosira pseudonana to ammonium, nitrate, silicate or phosphate starvation. Mã. Biol. 83: 51-59

Pengerud, B., Skjoldal, E. F., Thingstad, T. F. (1987). The reciprocal interaction between degradation of glucose and ecosystem structure. Studies in mixed chemostat cultures of marine bacteria, algae, and bacterivorous nanoflagellates. Mar. Ecol. Prog. Ser. 35: 111-117

Pirt, S. J. (1982). Maintenance energy: a general model for energy-limited and energy sufficient growth. Arch. Microbiol. 133: 300-302

Redfield, J. L., Ketchum, B. H., Rickards, F. A. (1963). The influence of organisms on the composition of seawater. In: Hill, M. N. (ed.) The sea, Vol. 2. J. Wiley \& Sons, New York, p. 26-77

Sakshaug, E., Olsen, Y. (1986). Nutrient status of phytoplank- ton blooms in Norwegian waters and algal strategies for nutrient competition. Can. J. Fish. Aquat. Sci. 43: 389-396

Schlegel, H. G. (1969). Allgemeine Mikrobiologie. Georg Thieme Verlag, Stuttgart, p. 16

Stouthammer, A. H. (1977). Energetic aspects of the growth of micro-organisms. In: Haddock, B. A., Hamilton, W. A. (ed.) Microbial energetics. Twenty-seventh Symp. Soc. Gen. Microbiol., Cambridge University Press, Cambridge, p. $285-315$

Tempest, D. W., Neijssel, O. M., Teixeira de Mattos, M. J. (1985). Regulation of carbon substrate metabolism in bacteria growing in chemostat culture. In: Kulaev, I. S., Dawes, E. W., Tempest, D. W. (ed.) Environmental regulation of microbial metabolism. Academic Press, New York, p. $53-69$

Thingstad, T. F., Pengerud, B. (1985). Fate and effect of allochthonous organic material in aquatic ecosystems. An analysis based on chemostat theory. Mar. Ecol. Prog. Ser. 21: $47-62$

Veldkamp, H. (1976). Continuous culture in microbial physiology and ecology. Meadowfield Press, Durham

This article was presented by Professor J. Gray; it was accepted for printing on November 12, 1986 